\title{
Averting the Crisis in Trainee Teacher Well-being - Learning Lessons across European Contexts: A Comparative Study
}

\author{
${ }^{1}$ Shaun Thompson, ${ }^{1}$ Emma Clarke, ${ }^{1}$ Aimee Quickfall, and ${ }^{2}$ Jonathan Glazzard \\ ${ }^{1}$ Bishop Grosseteste University, United Kingdom \\ ${ }^{2}$ Leeds Beckett University, United Kingdom
}

\begin{abstract}
Teacher well-being is frequently high-lighted as a significant contributor to poor retention rates. Whilst there remains a focus on the well-being of serving teachers and pupils, there is a paucity of research directly focusing on the well-being of trainee teachers. This pilot study sought to compare the experiences of trainee teachers from three European countries, in an attempt to identify the resources and challenges faced by teachers during their training. Through the use of interviews and visual approaches, key factors, which appeared to influence trainee teachers' well-being, were identified. Through shifting the focus of training onto the development of communities of practice, the development of interpersonal skills, and supporting the development of strong relationships, it is hoped that Initial Teacher Training (ITT) programmes in England can draw on some best practice from other European contexts to better support trainee teachers' well-being.
\end{abstract}

Keywords: well-being; initial teacher training (ITT), teacher retention, resources, challenges

\section{Introduction}

In England, 42,430 full-time equivalent (FTE) teachers entered the profession in 2017 ( Department for Education [DfE], 2017b). Whilst this figure appears to paint a positive picture in terms of teacher recruitment, when considered against the number of FTE teachers leaving the profession in the same year - 42,830 (DfE, 2017b), the outlook becomes less encouraging. 
Retention rates for teachers in England have gradually worsened since 2011, when $80 \%$ of teachers remained in the profession after three years of qualifying, dropping to 73\% in 2017 (Worth, 2018). The five-year retention rates paint an even bleaker picture, with $73 \%$ remaining in the profession after five-years in 2011, compared to just 67\% in 2017 (Worth, 2018) and this trend is continuing (Office for Standards in Education, Children's Services and Skills [Ofsted], 2019). In stark contrast, according to a 2013 survey, approximately $90 \%$ of Finnish teachers remain in the profession for the duration of their teaching careers (National Center on Education and the Economy, 2019).

In an attempt to understand the reasons behind such teacher attrition in England, several studies have been conducted (DfE, 2016). Amongst the most commonly cited reasons for teachers leaving the profession are: workload; stagnant pay; a lack of adequate work-life balance; a sense of disempowerment; and over-bearing accountability systems (Scott, 2016; National Education Union [NEU], 2019; Ofsted, 2019). In response to such findings, DfE provided guidance for schools and teachers in terms of tackling workload (DfE, 2018a). Nevertheless, according to the Teacher Wellbeing Index published in $2018,67 \%$ of teachers described themselves as stressed and $74 \%$ reported the inability to switch off and relax, contributing to a poor work-life balance (Education Support Partnership, 2018).

Supporting the well-being of serving teachers, and pupils, has become the focus of policy and research over recent years (Bonnell et al., 2014; DfE, 2017a; Ofsted, 2019). However, there remains a paucity of research and guidance for those individuals currently enrolled on initial teacher training (ITT) programmes. Although well-being forms an integral part of many ITT curricula, albeit to varying degrees, the focus of this tends to be on supporting pupils' well-being. Furthermore, it is often embedded within other priorities, such as child protection (Byrne et al., 2015), rather than being considered a discrete subject - as is the case in Finland.

In addition to a focus on well-being for pupils, the drive to consider the well-being of serving teachers is ongoing. A recent government report suggests that well-being at work is a significant 
factor in an individual's overall well-being, with educational professionals reporting the highest cases of work-related mental illness of any working group in Britain. Furthermore, the report goes on to state that overall job satisfaction, relationships and a sense of belonging all contribute to a positive sense of well-being (Ofsted, 2019).

In England, in 2018/19, 29,255 trainee teachers enrolled onto postgraduate ITT courses, compared to 5,335 onto undergraduate ITT courses (DfE, 2018b). Despite being the most common ITT route in England, the postgraduate ITT route is extremely short, being just 38 weeks, creating a high-intensity programme. The majority of ITT routes in neighbouring European countries share more similarities with the undergraduate ITT route in England, typically ranging in length from 3-5 years. However, whilst well-being and workload are inevitably addressed and embedded in varying degrees on postgraduate ITT programmes, clearly there is much room for improvement given the current retention statistics. Although there are no published figures for the withdrawal rates of students enrolled onto postgraduate ITT courses, the five-year retention rates for teachers trained on postgraduate routes is the lowest, at just $58 \%-61 \%$ (IFS, 2016). Of those students withdrawing from postgraduate routes, the most commonly cited reason is workload. Furthermore, of those trainees completing the programmes, the impact of workload on their personal lives has been identified as a common issue (Challen, 2005).

\section{The Current Study}

Given the current teacher retention rates in England; the paucity of research into the well-being of ITT students; and the intensity of the postgraduate ITT programmes, this pilot study sought to identify best practice from neighbouring European countries, in terms of supporting well-being for this group of students. Despite the reported well-being of teachers new to the profession ( $<2$ years) being higher than those longer-serving teachers (Ofsted, 2019), the rapid decline in well-being and its impact on retention is an area which requires more focus. Although most ITT programmes in other European countries are far from comparable in terms of the length of time spent training, this pilot study set out to explore the similarities and differences in terms of trainee teacher well-being, 
between European institutions. It is anticipated that through identifying best practice models and comparing factors contributing (positively or negatively) to well-being for this group of students, lessons may be learned to support and enhance well-being for those students enrolled on postgraduate ITT programmes in England.

Despite a lack of consensus amongst researchers as to a clear and consistent definition of wellbeing (Dodge et al., 2012; Pollard \& Lee, 2003; Putwain, 2007), this pilot study used the following conceptual lens, adapted from Dodge et al. (2012): maintaining the balance between resources and challenges; these factors may be internal or external and operate in a dynamic flux over time. The conceptual lens, which was used to ascertain participants' contributing factors pertaining to wellbeing, was presented to participants as a 'see-saw' visual representation of maintaining this balance (see Figure 1). Such lens captures the dynamic nature of well-being, as a fluid concept, enabling time to be a factor of consideration. The resources and challenges provide a personal approach to considering both internal and external factors, which may impact upon participants' well-being.

\section{Figure 1}

The Well-Being See-Saw Used to Identify Resources and Challenges, Faced by Students, during Their ITT Programmes (Adapted from Dodge et al., 2012)

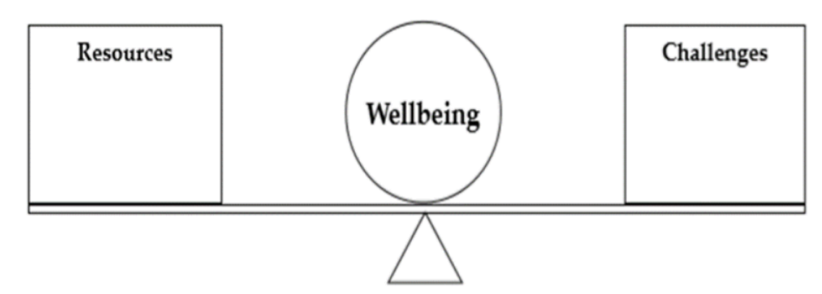

\section{Research Questions}

1. What are the significant challenges, which impact upon the well-being of trainee teachers?

2. What resources do trainee teachers draw upon to support their well-being?

3. What measures can Higher Education Institutions (HEIs) put in place to support the wellbeing of trainee teachers? 


\section{Participants and Ethics}

The pilot study involved a total of twenty-one ITT students, six academic staff and two newlyqualified teachers, from universities offering ITT programmes in three European countries (Table 1). Table 1

The Geographical Spread of the Participants in the Current Study

\begin{tabular}{lccc}
\hline $\begin{array}{c}\text { Location of the ITT } \\
\text { institution }\end{array}$ & Number of students & $\begin{array}{c}\text { Number of academic } \\
\text { staff }\end{array}$ & $\begin{array}{c}\text { Number of newly- } \\
\text { qualified teachers }\end{array}$ \\
\hline Denmark & 6 & 2 & 2 \\
Finland & 5 & 2 & 0 \\
England & 10 & 2 & 0 \\
Total & 21 & 6 & 2 \\
\hline
\end{tabular}

Denmark and Finland were selected within the current study, due to Denmark's similar approaches towards education and Finland's consistently high performance in international comparative assessments, such as the Programme for International Student Assessment (PISA) (Organisation for Economic Co-operation and Development [OECD], 2012). One institution was selected for the study from each country. The selection of the institution was made based on the similar courses in teacher education offered, along with similar sized institutions. Each of the institutions offered ITT programmes along with a wide variety of other courses. Information regarding the study was presented to programme leaders prior to recruitment of participants. Programme leaders recruited participants from the cohorts of students currently enrolled onto the ITT programmes. Participants were recruited from those currently enrolled onto teacher education programmes, who had also undertaken at least one period of school experience. This was deemed significant, as the researchers sought to identify the range of factors (both academic and practical) which impacted upon trainee teachers' well-being throughout the various cycles within their training. The information regarding the study was shared with the cohort, by the programme leaders. Participants were then invited to attend interviews, on a voluntary basis, which were held at a pre-determined time, as set out by the programme leaders. Despite the times scheduled for the interviews, the number of participants was still disappointingly low. This may have been due to additional academic work pressures, as the students were working on modules between school placements in each of the institutions visited 
during the data collection. All academic staff were involved with teaching on the ITT programmes and the newly qualified teachers were recent graduates (one year and six months post-qualification respectively). All students were aged between 18 and 24 years. Ethical consent was gained for the study from the researchers' own institution, and each of the host institutions, along with informed consent from each participant, prior to the research taking place. Participants were offered the right to withdraw at any point and fieldnotes were shared with the participants for validation.

\section{Methods}

All interviews and discussions were conducted in English. Each of the participants was fluent in English language. However, the use of paired discussions was offered to support individuals with expressing their perceptions and understandings.

\section{Semi-structured interviews}

Semi-structured interviews were carried out, either individually or as a group, to ascertain participants' understanding of well-being and to gain an insight into their perceptions of the ITT programme. Semi-structured interviews were used to ascertain an in-depth understanding of the factors which impacted upon the well-being of ITT students, gained from the trainee teachers' and academic staff perspectives. A key consideration in conducting any type of interview is the 'framing of real-life events' (Denzin \& Lincoln, 1994, p. 370), which the current study focused on through the various data collection methods. Such 'real-life events' were deemed an integral part of the data collection, as the researchers intended to gain an insight into the factors influencing the well-being of individuals who were currently, or recently, 'living' the experience of an ITT programme. Furthermore, the use of semi-structured interviews, as opposed to more formal, structured interviews, allowed for the use of probing questions and prompts (Denzin \& Lincoln, 1994). This, in turn, enabled the researchers to use a funnelling approach to gain deeper insight into the perspectives of the trainee teachers and the academic staff. Due to the interviews being conducted in English, which was a second language for those participants in institutions outside of England, clarification questions were used to confirm the researchers had correctly interpreted the 
participants' responses. Whilst the interviews were not digitally recorded, detailed fieldnotes were taken by two researchers independently during the interviews to enable researcher validation of the data. The fieldnotes were then used to support interpretation of the data (Kvale, 2007).

\section{Time-lining and visual methodologies}

In an attempt to elicit participants' personal experiences and to promote active collaboration between the participants and the researchers, visual approaches (time-lining, discussed below) were utilised (Banks, 2007; Hicks \& Lloyd, 2018; Pain, 2012; Stanczak, 2007).

The working definition of well-being used within this study was shared with each participant to ensure a shared understanding of the term used. However, in order to enable participants to draw on their personal experiences, they were then invited to reflect on the resources and challenges faced during their ITT programme, using the well-being see-saw model in Figure 1.

Whilst the ITT students and newly qualified teachers reflected on their own well-being, academic staff were asked to consider the challenges they felt the ITT students faced and the resources that were available to them throughout their training.

Following the well-being see-saw activity, participants were asked to timeline their training from the beginning of the programme to the current time (see Figure 2). Timelining enabled the participants to consider significant factors and events, which they felt had impacted upon their wellbeing (Adriensen, 2012). Time is not just experienced by the clock for trainee teachers; cycles emerge because of the nature of their movements through university and school communities, changing relationships and their understanding and experience. Furthermore, this approach attempts to remove the influence of the researchers' views on the participants' responses, thus reducing potential bias within the data (Ortega-Alcazar \& Dyck, 2012; Putwain, 2007). Visual methods are commonly interdisciplinary and used to explore participants' experiences (Hicks \& Lloyd, 2018) and have been increasingly reported in studies of well-being (Ortega-Alcázar \& Dyck, 2012). In conjunction with the interview and narrative discussion, timelining offers a mechanism to visually represent participants' perceptions and feelings (Ortega-Alcázar \& Dyck, 2012). Whilst it was 
suggested that participants may wish to consider the resources and challenges they had cited during the see-saw activity, they were offered the flexibility of personalising their timeline in a way which they felt best represented their own experiences.

\section{Figure 2}

The Timeline Offered to Participants to Map Their Resources, Challenges and Well-Being during Their ITT Programme

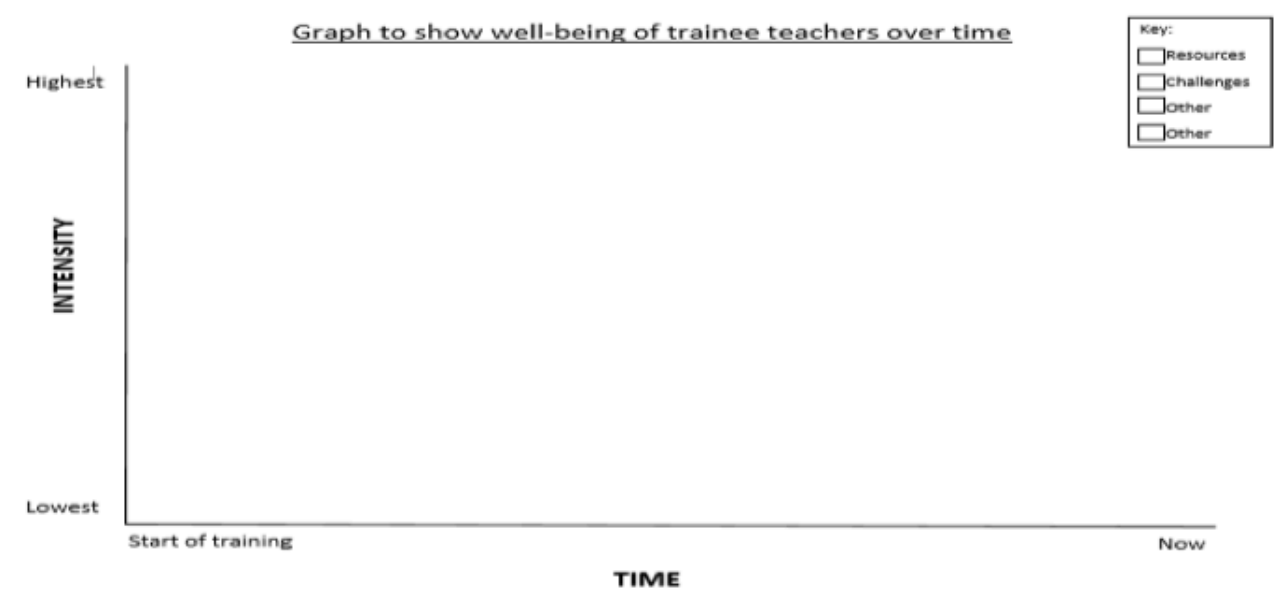

Following completion of the task, participants were asked to talk the researchers through their timelines; detailed fieldnotes were taken and validated by the participants prior to analysis.

The data from the 'see-saw' models and the timelines, along with the fieldnotes, were analysed by the researchers to generate emerging codes. The researchers deliberately avoided the use of a priori codes, as critics of a priori coding within social science studies argue that such a strategy may restrict accurate observation, and should therefore be avoided (Kettley, 2012, p. 95). Consequently, the researchers attempted to avoid pre-determined themes, which may have influenced the interpretation of the research data. The codes were assigned to each country and the role of the participants, before being aggregated into an overall set for the study. Such assignment to individual countries and roles, as well as the formation of an aggregated set, supported the researchers to carry out comparative analysis of the data across institutions.

\section{Findings}


The visual and narrative data collected was coded according to emerging key themes. Comparisons were made between participants within each individual institution as well as between institutions.

Prior to analysis of the narrative data and timelines, the researchers collated the data from the well-being see-saw activity to form an overview of the key codes emerging from this task (see Table 2). The emerging codes were aggregated from the range of participants.

\section{Table 2}

The Key Codes Emerging from the Well-Being See-Saw Task

\begin{tabular}{lc}
\hline \multicolumn{1}{c}{ Resources } & Challenges \\
\hline Teachers on placement & Coping \\
Family & Building relationships \\
Mentors (school and university) & Work-life balance \\
Group tutors & Assignments/academic work \\
Friends & Motivation \\
Sharing experiences & Confidence \\
Downtime & Knowing when to seek help \\
Knowledge and experience & Developing a routine \\
Literature/research & No 'one size fits all' \\
\hline
\end{tabular}

Using the emerging codes above, the narrative data from the interviews and timelines were analysed, generating themes which are discussed below. The themes were generated through aggregation of codes which encompassed similar data and key words from the participants.

\section{Comfort Zone}

Many of the trainee teachers made frequent reference to "feeling comfortable" and their "comfort zones" when considering their well-being at various points throughout their programme. Those times where individuals reported being more out of their comfort zone, for example, at the beginning of a programme and at the start of a teaching practice, coincided with lower levels of personal well-being.

Analysis of timelines and discussions with trainee teachers from all of the countries demonstrated a similar pattern between comfort zone and well-being. Whilst being out of one's comfort zone was seen to have its challenges, students in Finland were able to discuss the merits of this, in terms of a gradual development of coping strategies. One trainee teacher commented that, 
“whilst group work can present its own challenges, it can also be a resource. It enables you to draw on peers to develop strategies to manage the workload and pressure points." They referred to drawing on the resources they had gained as the programme progressed to gradually balance the reduction in well-being associated with moving out of their comfort zone. Here, they made specific reference to the importance of peer and colleague learning communities and relationships, also echoed by participants from Denmark. In contrast, within England, although trainees at the researchers' own institution are encouraged to form learning communities, the challenge of the lack of time spent with peers in the university setting was indicated as an obstacle to this. One student commented that, "although I try to make use of social media to maintain social networks, the lack of time and immense workload hinder this. Communicating through social media just isn't the same when you need a shoulder to cry on."

\section{Challenges}

Whilst many trainee teachers commented on the challenges they faced during their training, e.g. academic work, familiarising themselves with new schools, moving away from family, the academic staff in Denmark offered an alternative viewpoint to challenges and well-being. Although, as in Finland, trainee teachers are not explicitly reminded about the workload the beginning of the programme, the academic staff reported that the high intensity of the programme is a way of supporting students to develop their own coping strategies and therefore provides them with resources to offset the challenges. In contrast to the English context, the first three years of training in Denmark has a significant focus on group work within university sessions, thus the intensity (and development of associated coping strategies) is managed as a group. Only in the fourth and final year of training, do the trainees need to manage this intensity individually, by which time, they have drawn on their peers to develop and refine their own coping strategies.

\section{Workload}

To a certain extent, the impact of workload on well-being varied slightly between countries. One participant from Finland claimed that due to the high status of gaining an ITT place, she was 
prepared for significant workload, which in turn reduced the associated impact on well-being at the start of the programme. Furthermore, she went on to state how the significant workload was not repeatedly emphasised at the beginning of the course, rather this was something she experienced gradually and therefore developed strategies to manage it as it increased. She stated that, "we were very aware of the intensity and workload associated with the course when we applied. Our lecturers didn't emphasise this in sessions, it was just assumed that we already knew." This was echoed by a student in Denmark, who stated that "knowing tough periods are coming is worse than not knowing". In comparison to the researchers' experiences in their own institution in England, this was somewhat of a contrast. Some of the initial sessions on the researchers' own programmes draw trainees' attention to the sheer volume of workload ahead. Rather than support trainees with the gradual development of such workload management skills throughout the programme, trainees are provided with advice and guidance within these early sessions, potentially adding an increased stress factor from the start of the programme.

When analysing the timelines from English students, areas of intense workload and corresponding areas of reduced well-being, were associated with both academic work and school placements during the programme. This was in contrast to those students in Denmark, who made no indication of school placements impacting on an increase in workload and therefore a reduction in well-being. These students only commented on the impact of academic work throughout the programme as a significant factor contributing to increased workload.

\section{Maintaining Relationships}

The newly qualified teachers in Denmark highlighted the importance of strong relationships throughout their narratives. They identified a mis-match between the university training and what they referred to as "the real world". Here they discussed how the availability of staff within the university was greater than that of school-based staff, hence making it much easier to seek guidance and support when in university. To compound this issue, they reported that the structure of initial placements, where two days a week were spent in school and the rest in university, added to the 
challenge of being able to establish strong relationships with both the children and the school staff. They felt very strongly that knowing the school and the children contributed significantly to positive well-being.

A trainee teacher in Denmark reported on the importance of social networks for developing a "sense of belonging" and therefore enhancing well-being. He stated that, "whilst training in a large institution has its challenges, communication to new trainees regarding social events, and encouragement to participate in such events, is really important in developing the social networks that are needed to maintain a high level of well-being." He went on to state that "well-being can be significantly influenced by balancing social and academic work. Getting the right balance can be challenging, but once we have this, I think well-being is really improved." This was echoed by another trainee in Denmark, who felt that clear communication linked directly to an increase in wellbeing. Here, she discussed the importance of ease of access to information, both academic and social. Furthermore, she commented on the importance of the relationships between the academic staff and the students for promoting well-being.

One member of academic staff in Denmark promoted the importance of developing learning communities to support trainees. Within these communities, she suggested that the focus should be on the supporting relationships with other students and colleagues, and that these two areas had the biggest overall impact on trainee teacher well-being. This was supported by one of the trainee teachers who discussed the university sessions delivered to trainees on group conflict mediation and management. She emphasised the importance of these sessions in supporting trainees to develop strategies to manage difficult situations and how her skills had developed significantly in this area throughout these sessions.

\section{Discussion}

Teacher well-being has been acknowledged as a significant factor in the current retention crisis in England and has consequently become the focus of many recent reports, some of which provide policy recommendations to schools and educational establishments (Education Support 
Partnership, 2018; DfE, 2017a; 2018a; Ofsted, 2019). Despite the drive to tackle teacher well-being and retention, a paucity of research into those teachers currently in training on ITT programmes, remains. This comparative, pilot study has sought to explore the experiences of trainee teachers at institutions across three European countries to provide an insight into the factors affecting wellbeing for this group, along with the challenges and resources available to them in supporting their well-being.

Aligning with one of the significant factors contributing to a reduction in work-life balance, and subsequently personal well-being amongst serving teachers, is the challenge of workload (NEU, 2019; Ofsted, 2019; Scott, 2016). For trainee teachers throughout the European institutions within this study, workload is unsurprisingly a significant factor in terms of well-being. However, the role of academic work and school placements, in addition to the manner in which trainee teachers are supported to develop their skills in managing workload, differ across European institutions through programme design and delivery. Unlike English students, those in Denmark and Finland appeared to make little, or no relation between school placements and workload. Furthermore, rather than being made aware of the workload to be expected on ITT programmes in England, the interviews with those trainee teachers in Denmark and Finland suggest a subtler approach, with a focus on providing opportunities to develop skills in managing workload. Linking closely to the role of peer and colleague relationships, which are also a significant driver in the overall well-being of serving teachers in the workplace (Ofsted, 2019), the development and utilisation of communities of practice appears to be a key resource in managing workload and thus supporting well-being. Finnish and Danish ITT programmes appear to embed opportunities for developing these relationships, through conflict resolution and management, and plentiful instances for group work, particularly early on in the programme thus enabling workload management strategies to be developed collaboratively.

Such development of skills early on, and throughout these programmes, may enable trainee teachers to be better equipped for moving out of their comfort zone. Furthermore, such skills may 
support these trainee teachers in dealing with some of the challenges faced whilst on school placement, hence the lack of correlation between workload/well-being and school experience.

The time constraints of the English postgraduate ITT programmes result in a very tightly packed curriculum, with significant focus on subject and pedagogical knowledge and skills. Through drawing on the programme design from the Finnish and Danish ITT programmes, perhaps more time should be devoted to developing trainee teachers' personal, and interpersonal skills, which, in turn, may support them to be better equipped at dealing with challenges faced during school placements. Nevertheless, the structure and organisation of school placements suggests that blocks, rather than part-weeks, may be more advantageous in terms of developing relationships with school staff and pupils, and subsequently supporting the well-being of trainee teachers.

Through considering the balance of resources and challenges that trainee teachers draw upon, and face, during their training, through the use of the see-saw construct, the researchers have been able to identify the factors influencing the balance between the two. Such factors impacting upon this balance can enable programme leaders to consider the overall structure and design of ITT programmes in an attempt to maintain this balance.

\section{Conclusion and Recommendations}

Teacher well-being appears to be at the forefront of the retention crisis in England (Education Support Partnership, 2018; NEU, 2019; Ofsted, 2019; Scott, 2016). Although similar challenges, which inevitably impact upon well-being, are faced by trainee teachers on ITT programmes throughout European institutions, this pilot study has highlighted some subtle differences in programme design and delivery, which may provide a stepping stone to enhancing well-being amongst trainee teachers in England, and beyond. The significant factors impacting upon the well-being of both serving teachers, and trainee teachers, appears deep-rooted in workload and relationships.

Through drawing on the strategies deemed to be most successful at supporting well-being amongst trainee teachers throughout these European institutions, consideration should be given to 
embedding and supporting trainee teachers' development of personal, and interpersonal skills, alongside subject and pedagogical knowledge. Furthermore, ITT providers should avoid increasing stress and anxiety levels of trainee teachers with regards to workload, through providing resources to aid the ongoing development of those management skills needed, rather than highlighting workload as an issue.

Finally, through careful structure and organisation of ITT programmes, school placements may become a reduced factor when it comes to workload and subsequently enhanced well-being during these periods. Through embedding opportunities for collaborative work to develop communities of practice and considering the balance between pedagogical knowledge and interpersonal skills, the structure of ITT programmes in England may be able to be developed to better support trainee teachers' well-being. Through supporting trainee teachers to become equipped with skills in conflict resolution and coping mechanisms for workload, in conjunction with block placements, which follow on from these skills development sessions, a significant aspect of the ITT programme may potentially become less of a challenge to well-being and more of an opportunity to draw on resources gained from the programme.

Based on the findings from the current study, the above recommendations can be considered in the ongoing programme design and implementation of ITT programmes in England. Through minor adjustments to the organisation and delivery of such programmes, it is hoped that the issue of trainee teacher well-being may become a more prominent consideration in ITT programmes in England.

\section{Author Note}

Shaun Thompson is a senior lecturer in primary education and ITE Regional Partnership Lead at Bishop Grosseteste University. His teaching areas of interest are mathematics, special education 
and autism. His research includes mathematical problem solving and autism, along with well-being in teacher education.

Emma Clarke is a senior lecturer in primary education at Bishop Grosseteste University. She leads the 5-11 cohort on the primary PGCE programme. Her areas of interest and teaching focus on behaviour, the role of teaching assistants and science. Her research focuses on those areas along with well-being in teacher education.

Aimee Quickfall is Head of Programmes (Primary and Early Years) at Bishop Grosseteste University. Her areas of teaching focus on English, Phonics and the EYFS. Her areas of research focus on the roles of teacher mothers, narrative research and broader issues around gender in schools, as well as well-being within teacher education.

Jonathan Glazzard is professor of inclusive education at Leeds Beckett University. His research areas include LGBTQ+, inclusion, special educational needs and mental health. He is a qualitative researcher, using a broad range of approaches, including narrative and visual methodologies.

Correspondence concerning this article should be addressed to Shaun Thompson, Bishop Grosseteste University, Longdales Rd, Lincoln LN1 3DY, United Kingdom. Email:

shaun.thompson@bidhopg.ac.uk

The authors would like to express their gratitude to the participants, and their host institutions for their contribution to the current study.

\section{References}

Adriensen, H. K. (2012). Timeline interviews: A tool for conducting life history research. Qualitative Studies, 3(1), 40-55.

Banks, M. (2007). Using visual data in qualitative research. Sage. 
Bonnell, C., Humphrey, N., Fletcher, A., Moore, L., Anderson, R., \& Campbell, R. (2014). Why schools should promote students' health and wellbeing. British Medical Journal. https://doi.org/10.1136/bmj.g3078.

Byrne, J., Shepherd, J., Dewhirst, S., Pickett, K., Speller, V., Roderick, P., Grace, M., \& Almond, P. (2015). Pre-Service teacher training in health and well-being in England: The state of the nation. European Journal of Teacher Education, 38(2), 217-233.

Challen, D. (2005). To teach or not to teach: Trainees' responses to the challenges faced during initial teacher training'. https://leeds.ac.uk/educol/documents/149748.htm.

Denzin, N., \& Lincoln, Y. (1994). Handbook of qualitative research. Sage.

Department for Education. (2016). Achievement of 15-year-olds in England: PISA 2015 national report.

https://www.gov.uk/government/uploads/system/uploads/attachment_data/file/574925/PI SA-2015_England_Report.pdf

Department for Education. (2017a). Supporting mental health in schools and colleges.

https://www.gov.uk/government/publications/supporting-mental-health-in-schools-and$\underline{\text { colleges }}$

Department for Education. (2017b). School workforce in England: November 2017. https://www.gov.uk/government/statistics/school-workforce-in-england-november-2017

Department for Education. (2018a). Reducing teachers' workload.

https://www.gov.uk/government/publications/reducing-teachers-workload/reducing-

teachers-workload

Department for Education. (2018b). Initial teacher training (ITT) census for the academic year 2018 to 2019, England'. https://assets.publishing.service.gov.uk/government/uploads/system/uploads/attachment_ data/file/759716/ITT_Census_2018_to_2019_main_text.pdf 
Dodge, R., Huyton, J., \& Sanders, L. (2012). The challenge of defining wellbeing. International Journal of Wellbeing, 2(3), 222-235.

Education Support Partnership (2018). Teacher wellbeing index 2018.

https://www.educationsupportpartnership.org.uk/sites/default/files/teacher_wellbeing_ind ex_2018.pdf.

Frith, H., \& Harcourt, D. (2007). Using photographs to capture women's experiences of chemotherapy: Reflecting on the method. Qualitative Health Research, 17(10), 1340-1350. https://doi.org/10.1177/1049732307308949.

Gubrium, J., \& Holstein, J. (2009). Analysing narrative reality. Sage.

Hicks, A., \& Lloyd, A. (2018). Seeing information: Visual methods as entry points to information practices. Journal of Librarianship and Information Science, 50(3), 229-238.

Institute for Fiscal Studies. (2016). The longer-term costs and benefits of different initial teacher training routes. https://core.ac.uk/download/pdf/199234416.pdf

Kvale, S. (2007). Doing interviews. Sage.

National Center on Education and the Economy. (2019). Finland: Teacher and principal quality. http://ncee.org/what-we-do/center-on-international-education-benchmarking/topperforming-countries/finland-overview/finland-teacher-and-principal-quality/

National Education Union. (2019). Teacher recruitment and retention.

https://www.teachers.org.uk/edufacts/teacher-recruitment-and-retention.

Organisation for Economic Co-operation and Development. (2012). PISA 2012 field trial problem solving framework. https://www.oecd.org/pisa/pisaproducts/46962005.pdf

Office for Standards in Education, Children's Services and Skills. (2019). Teacher well-being at work in schools and further education providers.

https://www.gov.uk/government/publications/teacher-well-being-at-work-in-schools-andfurther-education-providers 
Ortega-Alcazar, I., \& Dyck, I. (2012). Migrant narratives of health and well-being: Challenging 'othering' processes through photo-elicitation interviews'. Critical Social Policy, 32(1), 106125.

Pain, H. (2012). A literature review to evaluate the choice and use of visual methods. International Journal of Qualitative Methods, 11(4), 303-319.

Pawson, R. (1996). Theorizing the interview. The British Journal of Sociology, 47(2), 295-314.

Pollard, E., \& Lee, P. (2003). Child well-being: A systematic review of the literature. Social Indicators Research, 61(1), 59-78.

Putwain, D. (2007). Researching academic stress and anxiety in students: Some methodological considerations. British Educational Research Journal, 33(2), 207-219.

Scott, S. (2016, June 30). Highest teacher leaving rate in a decade - and 6 other things we learned about the school workforce. Schoolsweek.Co.Uk. https://schoolsweek.co.uk/highestteacher-leaving-rate-in-a-decade-and-6-other-things-we-learned-about-the-schoolworkforce/

Stanczak, G. (2007). Introduction: Images, methodologies and generating social knowledge. In G. Stanczak (Ed.), Visual research methods: Image, society and representation (pp. 1-23). Sage. Worth, J. (2018, June 28). Latest teacher retention statistics paint a bleak picture for teacher supply in England'. National Foundation for Educational Research. https://www.nfer.ac.uk/newsevents/nfer-blogs/latest-teacher-retention-statistics-paint-a-bleak-picture-for-teachersupply-in-england/ 